\section{Respiratory Behavior of Cherimoya (Annona cherimola Mill.) under Controlled Atmospheres}

\author{
Teresa Palma and David W. Stanley' \\ Department of Food Science, University of Guelph, Guelph, Ont. NIG 2W1, \\ Canada
}

\author{
José M. Aguilera ${ }^{2}$ and Juan P. Zoffoli ${ }^{3}$ \\ Pontificia Universidad Católica de Chile, Vicuña Mackenna 4860, Santiago, \\ Chile
}

Additional index words. postharvest, ethylene, storage

\begin{abstract}
The objective of this work was to obtain information for designing modifiedatmosphere packages for storing and transporting cherimoyas. Respiration rates of 'Conchs Lisa' cherimoyas at $10 \mathrm{C}$ were monitored in a flow-through system using $\mathbf{O}_{2}$ consumption and $\mathrm{CO}$, production under atmospheres containing $5910,10 \%, 15 \%$, or $20 \%$ $\mathrm{O}_{2}$. Under normal atmosphere $\left(20 \% \mathrm{O}_{2}\right)$, the respiration curve exhibited atypical climacteric rise 15 days after harvest, while $15 \%$ and $10 \%$ delayed this event. Fruit kept in $5 \%$ $\mathrm{O}_{2}$ did not show a detectable climacteric rise and did not produce ethylene. All fruit ripened normally after being transferred to air storage at $20 \mathrm{C}$; however, the time needed to reach an edible condition differed with treatment and was inversely proportional to $\mathrm{O}$, content. Delay of the climacteric by $5 \% \mathrm{O}_{2}$, coupled with the continued ability to ripen, makes this procedure suitable for controlled- or modified-atmosphere cherimoya packaging.
\end{abstract}

The cherimoya is a subtropical fruit belonging to the Annonaceae family (Schroeder, 1956). Other edible fruits of this genus are obtained from Annona squamosa, A. muricata, and $A$. atemoya, all subtropical, but with lower eating quality than cherimoya (Brown et al., 1988; Córdoba, 1961). Commercial cherimoya orchards exist in Argentina, Brazil, Bolivia, Chile, Colombia, Pent, Venezuela, California, Italy, Spain, Egypt, Israel, New Zealand, and South Africa, but this fruit can be found in small gardens throughout all subtropical regions of the world.

As with most subtropical fruit, cherimoyas are highly perishable. They exhibit a high respiration rate, elevated ethylene production, and fast ripening, as evidenced by rapid pulp softening and flavor and aroma development. Thus, although grown in many subtropical areas, trading cherimoyas commercially has been limited.

Traditional refrigerated storage below 10C cannot be used with this fruit since it is susceptible to chilling injury (CI) (Reginato, 1980). Therefore, an alternative treatment that can be

Received for publication 30 June 1992. Accepted for publication 4 Dec. 1992. This work was supported in part by the Natural Sciences and Engineering Research Council of Canada. We gratefully acknowledge TransFresh Corp. (Santiago, Chile), in whose laboratory this work was done, and Cesa Nagel for providing the fruit. The cost of publishing this paper was defrayed in part by the payment of page charges. Under postal regulations, this paper therefore must be hereby marked advertisement solely to indicate this fact.

To whom reprint requests should be addressed

Dept. of Chemical Engineering.

${ }^{3}$ Dept. of Fruit Culture and Oenology. combined with moderate temperatures $(\geq 10 \mathrm{C})$ is necessary to delay ripening before this fruit can be introduced successfully to the large North American market.

Using a controlled or modified atmosphere in conjunction with storage at $10 \mathrm{C}$ would seem to be a logical alternative, but designing such packaging requires basic information about the influence of $\mathrm{O}_{2}$ levels on respiration rates. Little is known about the response of cherimoyas to controlled atmosphere, as presented in a review by Palma et al. (1992). The objective of this work was to obtain information regarding the respiration rates of maturegreen cherimoyas at several $\mathrm{O}_{2}$ levels as related to fruit ripening ability and final quality. These data are needed to achieve successful modified-atmosphere packaging.

Fruit. This study was conducted in Sept. and Oct. 1990. 'Conchs Lisa' cherimoyas were harvested from a commercial orchard of vigorous mature trees in La Crutz, Chile. This variety was selected for its low susceptibility to $\mathrm{CI}$ and high resistance to mechanical injury, characteristics that enhance its export potential. To obtain uniform fruit, flowers were hand-pollinated on the same day and only the resulting fruit were used.

Fruit were harvested 240 days after pollination after a slight change in peel color. Thirty undamaged fruit of uniform size and shape were selected for this work. Six fruit were analyzed the day after harvest to test initial maturity. The other 24 were dipped in fungicide and distributed randomly to each of

Storage. Fruit were stored in a refrigerated chamber under controlled temperature and continuous air flow. Since cherimoyas are the four treatments. susceptible to $\mathrm{CI}$, the storage temperature was set at $10 \pm 0.2 \mathrm{C}$, a level considered to be nonchilling for this variety (Reginato and Lizana, 1980). Cherimoya respiration was measured in several low- $\mathrm{O}_{2}$ atmospheres that were obtained by maintaining a continuous flow of the desired gas mixtures as follows: $\mathrm{T}_{\text {, }}$, $20 \% \pm 1.0 \% \mathrm{O}_{2}+80 \% \mathrm{~N}_{2} ; \mathrm{T}_{2}, 15 \% \pm 0.5 \% \mathrm{O}$ $+85 \% \mathrm{~N}_{2} ; \mathrm{T}_{3}, 10 \% \pm 0.5 \% \mathrm{O}_{2}+90 \% \mathrm{~N}_{2}$; and $\mathrm{T}_{4}, 5 \% \pm 0.3 \% \mathrm{O}_{2}+95 \% \mathrm{~N}_{2}$.

Fruit were maintained in individual storage chambers with the desired atmosphere for 30 days. Half of the replications (three fruit) was removed to ripen. The remaining three samples were left until day 43 to ripen. Ripening conditions consisted of a chamber at $20 \mathrm{C}$ and high $(285 \%)$ relative humidity; ripening took 0to 11 days, depending on the treatment.

Analysis. Headspace gas samples were taken and analyzed in a gas chromatography (model 8610; Scientific Research Instruments, Torrance, Calif.) connected to a thermal conductivity detector capable of quantifying $\mathrm{CO}_{2}$, $\mathrm{O}_{2}$, and $\mathrm{N}_{2}$ and a flame ionization detector that quantified ethylene. Samples were taken alternately from the entrance and from each outlet for each fruit. Respiratory rate was calculated as $\mathrm{O}_{2}$ consumption and $\mathrm{CO}_{2}$ production using the formula $\mathrm{R}=(\Delta \% \times \mathrm{F} \times 60) /(100 \times \mathrm{W})$, where $\Delta \%$ is the difference between the inlet and outlet concentration, $F$ is the flow in milliliters per minute, and $\mathrm{W}$ is the sample weight in kilograms. Ethylene was detected from the same sample taken for respiration measurement. Data were obtained as a percentage of the maximum peak observed, corrected by a flow factor, and, therefore, can be used only to compare treatments. The detection limit for ethylene was $0.1 \mathrm{ppm}$.

Quality. Quality was assessed after ripening and included pulp resistance to pressure, measured using a manual pressure tester with a $10-\mathrm{mm}$ probe; soluble solids concentration (SSC), measured with a thermoeompensated manual refractometer; pulp starch content, estimated by dyeing samples with an iodine solution ( $24 \mathrm{~g}$ of $\mathrm{KI}+12 \mathrm{~g} \mathrm{I} /$ /iter distilled water) followed by visual evaluation; epidermal color; and the presence of characteristic aroma and flavor.

Respiration patterns. Fruit kept at 10C with 207002 showed a typical climacteric rise (Fig. 1). Carbon dioxide production and $\mathrm{O}_{2}$ consumption values were lower than those reported by others, mainly because most of their data were obtained at higher temperatures (Biale et al., 1954; Brown et al., 1988; Reginato, 1980). Despite this low-temperature effect, cherimoyas exhibit a high respiration rate similar to that of avocados (Persea americana Mill.) and bananas (Muss $\times$ paradisiaca L.) (Wills et al., 1989). High standard deviations of the respiration data can be attributed to the natural variability of biological material, but they may be due also to out-of-phase ripening of individual fruit within each treatment, even though pollination occurred the same day.

After day 15, the rise in respiration, as $\mathrm{O}_{2}$ consumption or $\mathrm{CO}_{2}$ production, is characteristic of climacteric fruit and has been observed 

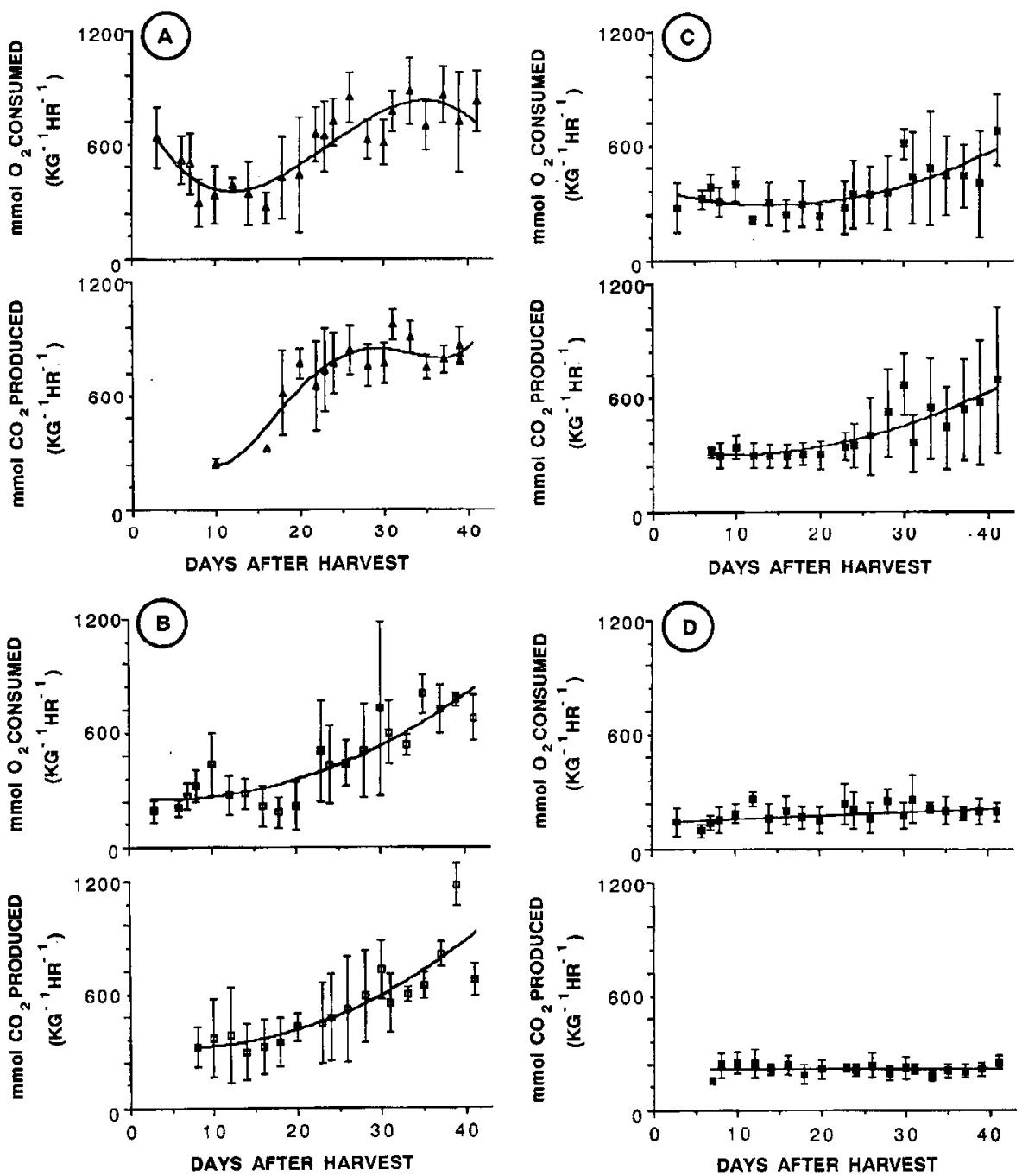

Fig. 1. Respiration rates of 'Conchs Lisa' chenmoya fruit kept at $10 \mathrm{C}$ and $\mathrm{O}_{2}$ concentrations of(A) $20 \%$, (B) $15 \%$, (C) $10 \%$, and (D) $5 \%$. Curves represent best-fit regression of six replications. Vertical bars represent SDS.

by others studying cherimoya (Biale et al., 1954; Brown et al., 1988; Reginato, 1980). On day 30 , softening had begun, and, by day 43 , the fruit were edible. Thus cherimoyas at $20 \%$ $\mathrm{O}_{2}$ behaved as a typical climacteric fruit, becoming edible after the climacteric.

A previously reported feature of the cherimoya respiratory pattern is a second rise after the climacteric (Brown et al., 1988; Kosiyachinda and Young, 1975; Reginato, 1980). We did not detect a second rise, probably because it occurred after the monitoring period.

In $10 \mathrm{w}-\mathrm{O}_{2}$ atmospheres, respiration rates are normally reduced, however, some authors have suggested that the cherimoya could be a special case, since higher $\mathrm{CO}_{2}$ production has been observed under controlled atmospheres (De la Plaza, 1980; Moreno and De la Plaza, 1983). Our data do not support this hypothesis; rather, they suggest that the cherimoya represents a normal climacteric fruit in which low$\mathrm{O}_{2}$ atmospheres reduce respiration rate (Fig. 1 A VS. B-D).

Fruit exposed to $15 \%$ or $10 \% \mathrm{O}_{2}$ showed a climacteric rise, but this occurred following the climacteric in 207002. Even though this rise was more pronounced with $15 \% \mathrm{O}_{2}$, fruit

1 D). These data, combined with the lack of at $20 \mathrm{C}$ in air.

${ }^{2}$ Soluble solids concentration. ethylene production (data not shown) and firmness retention, even at day 43 (Table 1), suggest that these samples may have started their climacteric only after they were removed from controlled atmosphere. Subsequently, these fruit developed characteristic aroma and flavor and softened normally during ripening at 20C in air (Table 1).

After 43 days in controlled atmosphere, fruit from $20 \% \mathrm{O}_{2}$ were soft, while those from $5 \% \mathrm{O}_{2}$ remained firm. This difference suggests that controlled atmosphere affects softening. Cherimoya pulp softens rapidly during ripening, and, for each cultivar, this softening is related directly to the fruit respiration rate (Peralta, 1984). Some fruit in 5\% $\mathrm{O}_{2}$ exhibited fungal growth after ripening at $20 \mathrm{C}$; this was likely the result of the prolonged (11 days) period needed for ripening. Previous reports (Palma et al., 1992) suggest that this problem can be solved by a stronger application of fungicides that are approved for use on cherimoya.

Ethylene production. Lack of adequate standards precluded the exact quantification of ethylene production. Comparing the results with the available standard indicated that the maximum ethylene level never exceeded 60 $\mu \mathrm{l} \cdot \mathrm{kg}^{-1} \cdot \mathrm{h}^{-1}$, which is low compared to the data of others (Biale et al., 1954; Brown et al., 1988; Kosiyachinda and Young, 1975; Reid, 1985). However, temperature has a marked effect on ethylene production, and, again, the lower temperature used in the present study probably explains these results.

No ethylene was detected from fruit in 5\% $\mathrm{O}_{2}$. In $10 \% \mathrm{O}_{2}$, half of the samples produced a detectable amount of ethylene, while the other half and all fruit in the $15 \%$ and $20 \% \mathrm{O}_{2}$ generated ethylene at increasing levels over time (data not shown). Oxygen concentrations $<8 \%$ limit production of and sensitivity to ethylene in some species (Kader, 1986). Further, in sealed packages where $\mathrm{O}_{2}$ level is reduced, ripening is retarded despite some ethylene accumulation (Knee, 1980). One explanation for this result is that the conversion of 1-aminocyclopropane- 1 -carboxylic acid to ethylene is inhibited by the lack of $\mathrm{O}_{2}$ (Yang, 198 1) and maybe the reason for the absence of ethylene production by cherimoyas in $5 \% \mathrm{O}_{2}$.

For each fruit, detectable ethylene levels followed the rise in respiration. This observation supports literature that classifies cherimoya as a fruit in which the climacteric pre-

Table 1. Quality evaluation of cherimoya fruit after controlled-atmosphere (CA) storage at 10C plus ripening

\begin{tabular}{|c|c|c|c|c|c|c|}
\hline \multirow{2}{*}{$\begin{array}{l}\text { CA } \\
\text { storage } \\
\text { (days) }\end{array}$} & \multirow{2}{*}{$\begin{array}{c}\mathrm{O}_{2} \\
\text { concn } \\
(\%)\end{array}$} & \multicolumn{2}{|c|}{ Quality after CA storage } & \multicolumn{3}{|c|}{ Ripening characteristics } \\
\hline & & Skin color & $\begin{array}{c}\text { Tactile } \\
\text { firmness }\end{array}$ & $\begin{array}{c}\text { Days to } \\
\text { ripen }\end{array}$ & $\begin{array}{c}\text { Firmness } \\
\text { (N) }\end{array}$ & $\begin{array}{l}\mathrm{SSC}^{\mathrm{z}} \\
\left({ }^{\circ} \mathrm{B}\right)\end{array}$ \\
\hline \multirow[t]{4}{*}{30} & 5 & Green, no pitting & Very hard & 11 & na $^{y}$ & na \\
\hline & 10 & Green, no pitting & Hard & 6 & $9.8 \pm 2.9$ & $18.4 \pm 3.3$ \\
\hline & 15 & Green, slight pitting & Hard & 6 & $8.8 \pm 1.0$ & $15.7 \pm 2.1$ \\
\hline & 20 & Green, some pitting & Slightly soft & 3 & $14.7 \pm 2.0$ & $18.4 \pm 0.2$ \\
\hline \multirow[t]{4}{*}{43} & 5 & Green, no pitting & Hard & 4 & $8.8 \pm 3.9$ & $18.5 \pm 0.6$ \\
\hline & 10 & Green, some pitting & Slightly soft & 2 & $9.8 \pm 1.0$ & $17.8 \pm 1.3$ \\
\hline & 15 & Green, some pitting & Slightly soft & 2 & $8.8 \pm 0.5$ & $15.2 \pm 0.9$ \\
\hline & 20 & Green, brown areas & Soft & 0 & $8.8 \pm 2.0$ & $15.3 \pm 1.3$ \\
\hline
\end{tabular}

y This sample suffered fungal attack during prolonged storage at $20 \mathrm{C}$ (11 days). 
cedes an increase in ethylene (Biale et al., 1954; Brown et al., 1988; Kosiyachinda and Young, 1975). However, in our work, only external headspace ethylene was measured, and a previous rise in internal ethylene could have occurred.

Ripening. All samples ripened normally after being transferred to $20 \mathrm{C}$ and normal air. Similar values for pulp resistance to pressure ( 8.8 to $14.7 \mathrm{~N})$ and for SSC $\left(\approx 17^{\circ}\right.$ Brix $)$ were obtained and characteristic aromas and flavors developed, but treatments differed in ripening time. Statistical analysis did not detect significant ( $P \leq 0.05]$ differences for any of the quality characteristics evaluated by a semitrained sensory panel (data not shown).

Fruit removed from controlled atmosphere on day 43 were allowed to ripen for 4 days at 20C. After that period, samples from $20 \% \mathrm{O}_{2}$ were overripe, their skin was completely dark, and an internal fungus had appeared. In contrast, fruit from $5 \% \mathrm{O}_{2}$ were acceptable, and their skin was green and healthy. Fruit from $10 \%$ and $15 \% \mathrm{O}_{2}$ were soft and partially overripe, and their skin was green with slightly depressed dark spots $\approx 3 \mathrm{~mm}$ wide. In some of these fruit, the spots were so close together that whole areas of the peel were dark. Samples of these areas were placed in a fungal culture medium, but none demonstrated colony proliferation. Similar spots have been described as symptoms of CI (Irarrázaval, 1984; Loyola, 1988) and senescence (Peralta, 1984; Reginato and Lizana, 1980) in cherimoyas. These two alternatives cannot be ignored, since it has been observed that CI and senescence have some characteristics in common (Kuo and Parkin, 1989) and it has been postulated that CI is a form of induced senescence (Stanley, 1991).

Lowering the atmospheric $\mathrm{O}_{2}$ level during storage decreased cherimoya respiration rates in this study. The data suggest that this effect is analogous to that in other climacteric fruits in which respiration rates are lowered and ripening is delayed. 'Conchs Lisa' cherimoyas can be maintained at $10 \mathrm{C}$ with $5 \% \mathrm{O}_{2}$ for up to 43 days and still ripen normally and remain acceptable after 4 days at room temperature. This feature, combined with the constant respiration rate obtained in this treatment, should facilitate designing a modifiedatmosphere package in which an active (as opposed to passive, in which the material is packaged in air or under a partial vacuum and respiration activity generates the desired atmosphere) initial modification is used and $\mathrm{CO}$, and ethylene levels are maintained close to zero. Further research should focus on the effects of these two gases. Commercializing such a treatment could lead to introducing this fruit in markets far from the growing area, using lower-cost transportation, such as ships equipped with controlled- or modified-atmosphere chambers, rather than air freight.

\section{Literature Cited}

Biale, J. B., R.E. Young, and A.J. Olmstead. 1954. Fruit respiration and ethylene production. Plant Physiol. 29: 168-174.

Brown, B. I., L.S. Wong, A.P. George, and R.J. Nissen. 1988. Comparative studies on the postharvest physiology of fruit from different species of Annona (custard apple). J. Hort. Sci. 63:521-528.

Córdoba, J.A. 1961. La chirimoya. Agricultural Tropical (Colombia) 17:647-664.

De la Plaza, J.L. 1980. Controlled atmosphere storage of cherimoya. Proc. XVth Intl. Cong. Refrigeration, Venice, Italy, 1979.3:701-712.

Irarrázaval, M.J. 1984. Respuesta de la chirimoya (Annona cherimola Mill.) al tratamiento de frío y encerado en postcosecha. Ing. Agr. Thesis, Pontificia Univ. Católica de Chile, Facultad de Agronomia, Santiago, Chile.

Kader, A.A. 1986. Biochemical and physiological basis for effects of controlled and modified atmospheres on fruits and vegetables. Food Technol. 40(5):99-104.

Knee, M. 1980. Physiological responses of apple fruit to oxygen concentrations. Ann. Applied Biol. 96:243-253.

Kosiyachinda, S. and R.E. Young. 1975. Ethylene production in relation to the initiation of respiratory climacteric in fruits. Plant Cell Physiol. 16:595-602.
Kuo, S. and K.L. Parkin. 1989. Chilling injury in cucumbers (Cucumis sativa L.) associated with lipid peroxidation as measured by ethane evolution. J. Food Sci. 54:1488-1491.

Loyola, E. 1988. Identificación y caracterización morfològica de los desórdenes fisiólogicos: Pitting, moteado y cristalización de la pulps en chirimoya cv. Conchs Lisa. Jag. Agr. Thesis, Univ. Católica de Valparaíso, Quillota, Chile.

Lyons, J.M. 1973. Chilling injury in plants. Annu. Rev. Plant Physiol. 24:445-466.

Moreno, J. and J.L. De la Plaza. 1983. The respiratory intensity of cherimoya during refrigerated storage: A special case of climacteric fruit? Acta Hort. 138:179-186.

Palma, T., J.M. Aguilera, and D.W. Stanley. 1992. A review of postharvest events in cherimoya (Annona cherimola Mill.). Postharvest Biol. Technol. 2:187-208.

Peralta, M.S. 1984. Maduración y almacenamiento de chirimoya (Annona cherimola Mill.) cvs. Conchs Lisa y Bronceada. Ing. Agr. Thesis, Univ. de Chile, Facultad de Ciencias Agrarias y Forestales, Santiago, Chile.

Reginato, G. 1980. Comportamiento de la chirimoya en frío (Annona cherimola Mill.) Ing. Agr. Thesis, Univ. de Chile, Facultad de Ciencias Agrarias y Forestales, Santiago, Chile.

Reginato, G. and L.A. Lizana. 1980. Alteraciones detectadas en chirimoyas (Annona cherimola Mill) durante el almacenamiento. Inv. Agrícola (Chile) 6(3):97-101.

Reid, M.S. 1985. Ethylene in postharvest technology, p. 68-74. In: postharvest technology of horticultural crops. Univ. of California, Div. of Agr. and Natl. Resources, Berkeley. Special Publ. 3311.

Schroeder, C.A. 1956. Cherimoyas, sapotes, and guavas in California. Calif. Avocado Soc. Yrbk. 40:49-51.

Stanley, D.W. 1991. Biological membrane deterioration and associated quality losses in food tissues. Critical Rev. Food Sci. Nutr. 30:487-553.

Wills, R.B.H., W.B. McGlasson, D. Graham, T.H. Lee, and E.G. Hall. 1989. Postharvest An introduction to the physiology and handling of fruits and vegetables. Van Nostrand Reinhold, New York.

Yang, S.F. 1981. Biosynthesis of ethylene and its regulation, p. 89-120. In: J. Friend and M.J.C. Rhodes (eds.). Recent advances in the biochemistry of fruits and vegetables. Academic, London. 